\title{
Magnesium sulphate therapy in eclampsia and pre-eclampsia
}

\author{
Smriti Sagar*, Neeta Natu, Nootan Chandwaskar
}

Department of Obstetrics and Gynecology, Sri Aurobindo Medical College, Indore, Madhya Pradesh, India

Received: 21 May 2018

Accepted: 26 June 2018

\section{*Correspondence:}

Dr. Smriti Sagar,

E-mail: smritisagar16.ss@ gmail.com

Copyright: (C) the author(s), publisher and licensee Medip Academy. This is an open-access article distributed under the terms of the Creative Commons Attribution Non-Commercial License, which permits unrestricted non-commercial use, distribution, and reproduction in any medium, provided the original work is properly cited.

\section{ABSTRACT}

Background: Maternal and perinatal mortality and morbidity remains high during pregnancy in the presence of eclampsia, it can have severe adverse effects on mother and the fetus. So, its management should be a top priority. The objective of the present research was to study the effect of magnesium sulphate in control of imminent eclampsia and eclampsia.

Methods: 19 cases of eclampsia and 185 cases of imminent eclampsia were treated with standardized magnesium sulphate. The outcome measures in terms of recurrence of convulsions, maternal and neonatal outcome, etc. were seen.

Results: Most common age group in both the groups were $21-30$ years (i.e. $78.9 \%$ with eclampsia and $75.7 \%$ with imminent eclampsia). In both the groups, majority of the women were primigravidae. In eclampsia group, 9 (47.4\%) women had 1 episode of convulsion, $8(42.1 \%)$ women had two episodes of convulsions, $1(5.3 \%)$ women each had 3 and 4 episodes of convulsions, while there were no convulsions in imminent eclampsia women (' $\mathrm{t}$ ' value $=28.558$, $\mathrm{df}=202, \mathrm{p}=0.000)$. Vomiting and headache $(94.7 \%)$ were the most common premonitory symptoms in eclampsia group, followed by edema in $68.4 \%$ women, while in imminent eclampsia $64.9 \%$ women had headache, $57.8 \%$ women had edema and $43.2 \%$ had vomiting. Recurrence of convulsions were seen in $4(21.1 \%)$ women of the eclampsia group even after giving maintenance dose and additional dose of magnesium sulphate. $1(5.3 \%)$ death was seen in eclampsia group and none in the imminent eclampsia group. Neonatal mortality in eclampsia group (47.4\%) was higher than imminent eclampsia group (11.7\%), which was statistically significant $(Z$ value $=3.05, p=0.002)$.

Conclusions: Magnesium sulphate regimen was effective in control of convulsions in eclampsia and as prophylaxis in imminent eclampsia.

Keywords: Convulsions during pregnancy, Eclampsia, Hypertension, Imminent eclampsia, Magnesium sulphate regimen

\section{INTRODUCTION}

Pre-eclampsia is a disorder of pregnancy in which there is high blood pressure and presence of large amounts of protein in the urine or other organ dysfunction. ${ }^{1,2}$ Eclampsia is the onset of seizures (convulsions) in a woman with pre-eclampsia. Onset may be before, during, or after delivery. Complications include aspiration pneumonia, cerebral hemorrhage, kidney failure, and cardiac arrest. Pre-eclampsia and eclampsia are a part of a larger group of conditions known as hypertensive disorders of pregnancy. Pre-eclampsia affects about 5\% of deliveries while eclampsia affects about $1.4 \%$ of deliveries. ${ }^{3}$ Hypertensive disorders of pregnancy are one of the most common causes of death in pregnancy. ${ }^{4}$

Recommendations for prevention include calcium supplementation, treatment of prior hypertension with medications., 5 The use of intravenous or intramuscular magnesium sulfate improves outcomes in those with 
eclampsia and is generally safe. ${ }^{7,8}$ Other treatments may include blood pressure medications such as hydralazine and emergency delivery of the baby either vaginally or by caesarean section.

Pritchard had popularized the use of magnesium sulphate therapy for eclampsia and preeclampsia. Commonest adverse effect seen was respiratory depression caused by magnesium sulphate. Hence, a lower dose of magnesium sulphate had also been tried and tested by various authors to see the effectiveness in the Indian context. ${ }^{9}$

The standard Pritchard regimen dose of magnesium sulphate is $4 \mathrm{gm}$ of $20 \% \mathrm{MgSO} 4 \mathrm{IV}$ followed by $10 \mathrm{gm}$ of $50 \% \mathrm{MgSO} 4 \mathrm{IM}$ (5gm in each buttocks)

The present study was undertaken to find out the outcome in terms of recurrence of convulsions in eclamptic women and to see if any convulsions occurred in imminent eclamptic women when magnesium sulphate was given prophylactically at studied institution.

The aim of the present research was to study the effect of MgSo4 in eclampsia and imminent eclampsia. Objectives of present study was to evaluate the efficacy of loading dose $\mathrm{MgSO}_{4}$ for control of convulsion in eclampsia and as a prophylaxis for convulsion in imminent eclampsia, to study the recurrence rate of convulsions in eclampsia and to study the neonatal outcome in both the cases.

\section{METHODS}

The present prospective, study was carried out at Department of Obstetrics and Gynaecology, Sri Aurobindo Medical College and Postgraduate Institute, Indore (M.P.) from December 2016 to January 2018. 19 women with eclampsia and 185 women with imminent eclampsia presenting to our institution during the study period were included in the study.

\section{Inclusion criteria}

- $\quad$ Period of gestation of more than 20 weeks

- No associated obstetric and medical complications.

\section{Exclusion criteria}

- Chronic hypertension

- History and examination suggestive of evidences of any medical disorders like chronic renal diseases, coarctation of aorta or essential hypertension

- Not willing for participating in the study.

\section{Treatment regimen for eclamptic women}

\section{Loading dose}

4 gm magnesium sulphate was given I/V (intravenous), diluted in $20 \mathrm{cc}$ of $5 \%$ dextrose, slowly over $15-20$ minutes.

\section{Maintenance dose}

5 gm magnesium sulphate I/M was given 4 hourly till 24 hours after delivery or after last convulsion whichever was later. 2,3

\section{For recurrence of convulsions}

If convulsions occurred half-an-hour after the loading dose, only then it was called recurrence of convulsions and in that case an additional dose of $2 \mathrm{gm} \mathrm{I} / \mathrm{V}$ or I/M was given, and previous dose scheduled of 4 hourly was continued as planned.

\section{Protocol for seizure prophylaxis in imminent eclampsia}

5 gm magnesium sulphate I/M was given 4 hourly and continued till premonitory symptoms and signs disappeared.

All the women were monitored on clinical criteria. Before each dose of magnesium sulphate toxicity in the form of deep tendon reflexes, urine output and respiratory rate was assessed.

Anti-hypertensives were given either sublingually or orally as an adjuvant therapy in patients who had systolic blood pressure $>160 \mathrm{~mm} \mathrm{Hg}$ or diastolic blood pressure $>110 \mathrm{~mm} \mathrm{Hg}$ to prevent cerebrovascular accidents.

Hydration was maintained with IV fluids without causing circulatory overload. Eclampsia women were encouraged to take fluids orally as soon as they recovered consciousness.

In all women of eclampsia and imminent eclampsia, routine investigations like $\mathrm{CBC}$, Urine routine and microscopy, kidney function tests, liver function tests and platelet count, ultrasonography with colour Dopple r(to find out the salvageability of the fetus), fundoscopy, etc. were done.

Termination of pregnancy was undertaken in all cases of eclampsia. Delivery was expelled in the form of induction / augmentation of labor. Decision regarding termination of pregnancy in cases of imminent eclampsia depended on severity of disease and maturity of the fetus. In patients of imminent eclampsia who were far from term, if symptoms and signs of imminent eclampsia disappeared after magnesium sulphate prophylaxis, the pregnancy was continued till 37 weeks wherever possible. Decision for termination was taken, if premonitory symptoms persisted or pregnancy was 37 weeks for more.

\section{Outcome measures}

Maternal outcome, neonatal outcome, recurrence of convulsions, death, etc. 


\section{Statistical analysis}

The mean comparison between the groups was done using Unpaired ' $t$ ' test. Association between nonparametric variables were done using Pearson Chi-square test, proportional comparisons were done using $\mathrm{Z}$ test for two sample proportion. A $p$ value of $<0.05$ was taken as statistically significant.

After obtaining the approval from the Ethics Committee of Sri Aurobindo Medical College and Postgraduate Institute, Indore, the study was initiated. Also prior to enrollment of each woman a written voluntary informed consent was obtained from woman and/or her legally acceptable representative.

All the women were treated according to the standard protocol for the management of eclampsia and imminent eclampsia as mentioned above. All the treatment costs were borne by the woman herself. No additional procedure/test was conducted for the specific requirement of the study. Hence, there were no additional financial burden on the woman or on the institution. All the costs related to the conduct of the study were borne by the investigator.

\section{RESULTS}

In all 204 women were included, of them 19 (9.3\%) women with eclampsia and $185(90.7 \%)$ women with imminent eclampsia were included in our series. Majority of the women belonged to the age group 21-30 years (i.e. $78.9 \%$ with eclampsia and $75.7 \%$ with imminent eclampsia).

Table 1: Total number of convulsions in eclampsia.

\begin{tabular}{|c|c|c|c|c|c|c|}
\hline \multirow{2}{*}{$\begin{array}{l}\text { Number of } \\
\text { convulsions }\end{array}$} & \multicolumn{2}{|c|}{ Eclampsia } & \multicolumn{2}{|c|}{$\begin{array}{l}\text { Imminent } \\
\text { eclampsia }\end{array}$} & \multicolumn{2}{|c|}{ Total } \\
\hline & No. & $\%$ & No. & $\%$ & No. & $\%$ \\
\hline None & 0 & 0.0 & 185 & 100.0 & 185 & 90.7 \\
\hline 1 & 9 & 47.4 & 0 & 0.0 & 9 & 4.4 \\
\hline 2 & 8 & 42.1 & 0 & 0.0 & 8 & 3.9 \\
\hline 3 & 1 & 5.3 & 0 & 0.0 & 1 & 0.5 \\
\hline 4 & 1 & 5.3 & 0 & 0.0 & 1 & 0.5 \\
\hline Total & 19 & 100.0 & 185 & 100.0 & 204 & 100.0 \\
\hline Mean \pm SD & \multicolumn{2}{|c|}{$1.68 \pm 0.82$} & \multicolumn{2}{|c|}{$0.00 \pm 0.00$} & & \\
\hline t value & \multicolumn{4}{|c|}{$28.558, \mathrm{df}=202$} & & \\
\hline$P$ value & \multicolumn{4}{|c|}{$0.000 *$} & & \\
\hline
\end{tabular}

In eclampsia group, majority of the women were primigravida $11(57.9 \%)$, followed by gravida $2-3$ i.e. 7 (36.8\%) and there was only 1 (5.3\%) woman with gravida $>3$. In the imminent eclampsia group, majority of the women, $84(45.4 \%)$ were primigravida, followed by gravida $2-3$ i.e. $78(42.2 \%)$ and there was only 23 $(12.4 \%)$ woman with gravida $>3$. In both the groups, majority of the women were primigravidae.
In the eclampsia group, $9(47.4 \%)$ women had 1 episode of convulsion, $8(42.1 \%)$ women had two episodes of convulsions, 1 (5.3\%) each woman had 3 and 4 episodes of convulsions (Table 1).

In the eclampsia group, 10 (52.6\%) women had blurring of vision, $18(94.7 \%)$ women each had vomiting and headache and $13(68.4 \%)$ women had edema. In the imminent eclampsia group, $2(1.1 \%)$ women had no premonitory symptoms, $7(3.8 \%)$ women had hyperreflexia, $22(11.9 \%)$ had blurring of vision, 80 (43.2\%) women had vomiting, $107(57.8 \%)$ women had edema and 120 (64.9\%) women had headache. Premonitory symptoms were more prevalent in the eclampsia group in comparison to the imminent eclampsia group (Table 2).

Table 2: Distribution of women according to premonitory symptoms in eclampsia and imminent eclampsia $(\mathrm{N}=\mathbf{2 0 4})$.

\begin{tabular}{|llllllll|}
\hline $\begin{array}{l}\text { Premonitory } \\
\text { symptoms }\end{array}$ & \multicolumn{2}{l}{ Eclampsia } & \multicolumn{2}{l}{$\begin{array}{l}\text { Imminent } \\
\text { eclampsia }\end{array}$} & \multicolumn{2}{l}{ Total } \\
\hline None & 0 & 0.0 & 2 & No. & \% & No. & $\%$ \\
\hline Hyperreflexia & 0 & 0.0 & 7 & 3.1 & 2 & 7 & 1.0 \\
\hline $\begin{array}{l}\text { Blurring of } \\
\text { vision }\end{array}$ & 10 & 52.6 & 22 & 11.9 & 32 & 15.7 \\
\hline Vomiting & 18 & 94.7 & 80 & 43.2 & 98 & 48.0 \\
\hline Edema & 13 & 68.4 & 107 & 57.8 & 120 & 58.8 \\
\hline Headache & 18 & 94.7 & 120 & 64.9 & 138 & 67.6 \\
\hline
\end{tabular}

The mean number of convulsions in the eclampsia group was $1.68 \pm 0.82$, while in the imminent eclampsia group it was $0.00 \pm 0.00$. The difference was found to be statistically significant (' $\mathrm{t}$ ' value $=28.558, \mathrm{df}=202$, $\mathrm{p}=0.000$ ). After the first loading dose of low dose magnesium sulphate 15/19 (78.9\%) women had control of convulsions in the eclampsia group, while $4(21.1 \%)$ women still had convulsions.

In the eclampsia group, all $19(100.0 \%)$ women were given maintenance dose, while in the imminent eclampsia group 168 (90.8\%) women were given maintenance dose. Of the 19 women in the eclampsia group after the maintenance dose, 15 (78.9\%) women were convulsion free, while 4 (21.1\%) women still had convulsions.

Additional maintenance dose was given in 15 (78.9\%) women with eclampsia, while no woman with imminent eclampsia received any additional dose of maintenance dose.

In eclampsia group, 13 (68.4\%) were admitted in ICU, 1 (5.3\%) woman had partial HELLP syndrome, in 4 (21.1\%) women, the outcome was good and 1 (5.3\%) woman expired; while in the imminent eclampsia group, $10(5.4 \%)$ women were admitted to ICU, 3 (1.6\%) women had sequel and 172 (93.0\%) women had good outcome (Table 3). 
Table 3: Distribution of women according to maternal outcome in eclampsia and imminent eclampsia $(\mathrm{N}=187)$.

\begin{tabular}{|lllllll|} 
Maternal & \multicolumn{2}{l}{ Eclampsia } & \multicolumn{2}{l}{$\begin{array}{l}\text { Imminent } \\
\text { eclampsia }\end{array}$} & \multicolumn{2}{l}{ Total } \\
Outcome & No. & $\%$ & No. & $\%$ & No. & $\%$ \\
\hline Death & 1 & 5.3 & 0 & 0.0 & 1 & 0.5 \\
\hline Good & 4 & 21.1 & 172 & 93.0 & 176 & 86.3 \\
\hline $\begin{array}{l}\text { ICU } \\
\text { admission }\end{array}$ & 13 & 68.4 & 10 & 5.4 & 23 & 11.3 \\
$\begin{array}{l}\text { Partial } \\
\begin{array}{l}\text { HELLP } \\
\text { syndrome }\end{array}\end{array}$ & 1 & 5.3 & 0 & 0.0 & 1 & 0.5 \\
\hline $\begin{array}{l}\text { Sequele } \\
\text { Total }\end{array}$ & 0 & 0.0 & 3 & 1.6 & 3 & 1.5 \\
\hline
\end{tabular}

There were total 19 deliveries in the eclampsia group and 188 deliveries in imminent eclampsia group. Of the 19 deliveries in the eclampsia group, 7 (36.8\%) neonates were discharged in well condition, $4(21.1 \%)$ were intrauterine deaths, $3(15.8 \%)$ required NICU stay, 4 $(21.1 \%)$ were still born and there was $1(5.3 \%)$ death. Total neonatal mortality in the eclampsia group was 9 $(47.4 \%)$ (Table 4).

Table 4: Distribution of women according to neonatal outcome in eclampsia and imminent eclampsia ( $\mathbf{N = 1 8 7 ) . ~}$

\begin{tabular}{|lllllll|}
$\begin{array}{l}\text { Neonatal } \\
\text { outcome }\end{array}$ & $\begin{array}{l}\text { Eclampsia } \\
(\mathbf{n = 1 9 )}\end{array}$ & $\begin{array}{l}\text { Imminent } \\
\text { eclampsia } \\
(\mathbf{n = 1 8 8})\end{array}$ & Total & \\
\hline Death & 1 & 5.3 & 7 & 3.7 & 8 & 3.9 \\
\hline Discharged & 7 & 36.8 & 153 & 81.4 & 160 & 77.3 \\
\hline IUD & 4 & 21.1 & 7 & 3.7 & 11 & 5.3 \\
\hline Macerated & 0 & 0.0 & 1 & 0.5 & 1 & 0.5 \\
\hline NICU stay & 3 & 15.8 & 13 & 6.9 & 16 & 7.7 \\
\hline Stillborn & 4 & 21.1 & 7 & 3.7 & 11 & 5.3 \\
\hline
\end{tabular}

While in the imminent eclampsia group, out of the 188 deliveries, $153(81.4 \%)$ neonates were discharged in well condition, $7(3.7 \%)$ neonates were late intrauterine deaths, $13(6.9 \%)$ neonates required NICU stay, 7 (3.7\%) neonates were stillborn, $1(0.5 \%)$ neonate was macerated and there were $7(3.7 \%)$ deaths post-delivery. Overall there were $22(11.7 \%)$ neonatal deaths in imminent eclamspia group (Table 4).

Table 5: Comparison of neonatal outcome in eclampsia and imminent eclampsia $(\mathrm{N}=187)$.

\begin{tabular}{|c|c|c|c|c|}
\hline \multirow{2}{*}{$\begin{array}{l}\text { Neonatal } \\
\text { outcome }\end{array}$} & \multicolumn{2}{|c|}{$\begin{array}{l}\text { Eclampsia } \\
(n=19)\end{array}$} & \multicolumn{2}{|c|}{$\begin{array}{l}\text { Imminent eclampsia } \\
(\mathrm{n}=\mathbf{1 8 8})\end{array}$} \\
\hline & No. & $\%$ & No. & $\%$ \\
\hline Death & 9 & 47.4 & 22 & 11.7 \\
\hline
\end{tabular}

$\mathrm{Z}$ test for two sample proportion applied; $\mathrm{Z}$ value $=3.05, \mathrm{P}$ value $=0.002 *$, significant
There was a higher proportion of neonatal deaths in the eclampsia group women in comparison imminent eclampsia women group $(Z$ value $=3.05, p=0.002)$, which was statistically significant (Table 5).

\section{DISCUSSION}

The present study was undertaken to compare the effect of low dose $\mathrm{MgSO} 4$ in eclampsia and imminent eclampsia. In the present study, in 15 (78.9\%) women convulsions were controlled in the eclampsia group and when given as prophylaxis in the imminent eclampsia group, none of the women of this group had any episode of convulsion. The recurrence rate of convulsions in our study was $21.1 \%$.

Study done by Nath et al also found a $94 \%$ control of eclampsia in their study group. ${ }^{10}$ They also reported no magnesium toxicity. Sardesai et al reported control of eclamptic fits in $90 \%$ women with low dose MgSO $4{ }^{9}$ Begum et al reported $98 \%$ control of eclamptic fits in their series. ${ }^{11}$

In present study there was $1(5.3 \%)$ maternal mortality in the eclampsia group, while Nath et al reported no maternal mortality in their study. ${ }^{10}$ Sardesai et al reported $2.63 \%$ maternal mortality in their series. ${ }^{9}$

In present study perinatal outcome was $47.4 \%$ in the eclampsia group and $11.7 \%$ in the imminent eclampsia group. Overall IUDs were 5.3\%, macerated still births were $0.5 \%$, still births were $5.3 \%$, and deaths were $3.9 \%$. Nath et al reported an overall perinatal mortality of $33 \% .{ }^{10}$ With $80 \%$ still births and $20 \%$ neonatal deaths. Sardesai et al reported $33.90 \%$ perinatal mortality in their study. ${ }^{9}$

Overall the magnesium sulphate was effective in control of convulsions in women with eclampsia and as a prophylaxis in women with imminent eclampsia.

Funding: No funding sources

Conflict of interest: None declared

Ethical approval: The study was approved by the Institutional Ethics Committee

\section{REFERENCES}

1. Lambert G, Brichant JF, Hartstein G, Bonhomme V, Dewandre PY. Preeclampsia: an update. Acta Anaesthesiol Belg. 2014;65(4):137-49.

2. American College of Obstetricians and Gynecologists; Task Force on Hypertension in Pregnancy. Hypertension in pregnancy. Report of the American College of Obstetricians and Gynecologists' Task Force on Hypertension in Pregnancy. Obstet Gynecol. 2013;122(5):1122-31.

3. Abalos E, Cuesta C, Grosso AL, Chou D, Say L. Global and regional estimates of preeclampsia and 
eclampsia: a systematic review. Eur J Obstet Gynecol Reprod Biol. 2013;170(1):1-7.

4. Arulkumaran N, Lightstone L. Severe pre-eclampsia and hypertensive crises. Best Pract Res Clin Obstet Gynaecol. 2013;27(6):877-84.

5. WHO recommendations for prevention and treatment of pre-eclampsia and eclampsia: Implications and Actions. Available at: http://apps.who.int/iris/bitstream/handle/10665/1196 27/WHO_RHR_14.17_eng.pdf?sequence $=1$. Accessed on 13.08.2017.

6. Henderson JT, Whitlock EP, O'Connor E, Senger CA, Thompson JH, Rowland MG. Low-dose aspirin for prevention of morbidity and mortality from preeclampsia: a systematic evidence review for the U.S. Preventive Services Task Force. Ann Intern Med. 2014;160(10):695-703.

7. Smith JM, Lowe RF, Fullerton J, Currie SM, Harris L, Felker-Kantor E. An integrative review of the side effects related to the use of magnesium sulfate for pre-eclampsia and eclampsia management. BMC Pregnancy Childbirth. 2013;13:34.
8. McDonald SD, Lutsiv O, Dzaja N, Duley L. A systematic review of maternal and infant outcomes following magnesium sulfate for preeclampsia/eclampsia in real-world use. Int $\mathbf{J}$ Gynaecol Obstet. 2012;118(2):90-6.

9. Sardesai S, Maira S, Patil A, Patil U. Low dose magnesium sulphate therapy for eclampsia and imminent eclampsia: regime tailored for Indian women. J Obstet Gynaecol Ind. 2003;53(6):546-50.

10. Nath J, Sharma R, Mahajan SS. A study on low dose magnesium sulphate regime for eclampsia in a tertiary care teaching hospital in North India. Biomed Pharmacol J. 2013;6(1):29-32.

11. Begum R, Begum A, Johanson R, Ali MN, Akhter S. A low dose ("Dhaka") magnesium sulphate regime for eclampsia. Acta Obstet Gynecol Scand. 2001;80(11):998-1002.

Cite this article as: Sagar S, Natu N, Chandwaskar N. Magnesium sulphate therapy in eclampsia and pre-eclampsia. Int J Reprod Contracept Obstet Gynecol 2018;7:3189-93. 